\title{
Emergency care for complainants of sexual assault
}

\author{
Martin Wiese MD MRCS ${ }^{1}$ Catherine Armitage MB BCh ${ }^{2}$ Jo Delaforce RGN $^{3}$ Jan Welch FRCP ${ }^{3}$
}

J R Soc Med 2005;98:49-53

Sexual assault in the UK is common. The British Crime Survey (2000) estimated that 61000 women in England and Wales had been raped in the preceding year and found that this is the crime that women fear most. ${ }^{1}$ Most women and virtually all men who have been sexually assaulted keep their painful experience to themselves and do not disclose it to police or healthcare services. ${ }^{2}$ Those vulnerable individuals miss out on the prevention and treatment of sequelae such as sexually transmitted infections, genital injuries and other trauma, unwanted pregnancies, and psychological morbidity - while their assailants avoid prosecution and may go on to assault others.

Even when sexual assault is reported to the police, conviction rates are low. In the year 2002, the police recorded 9723 female rapes. Only 2651 assailants were proceeded against and a mere 572 cases ended in a conviction. ${ }^{3}$ Service improvements that encourage complainants of sexual assault to seek help for themselves and provide the forensic evidence needed by the prosecution to secure a conviction are therefore clearly desirable.

\section{CONVENTIONAL MANAGEMENT AND ITS SHORTFALLS}

Care for complainants of sexual assault is currently fragmented. Emergency departments treating injuries may not always address other health issues arising from the assault such as post-coital contraception and screening for sexually transmitted infections. Expertise in the collection of forensic evidence is usually not available. Victims are therefore advised to report the event to the police, but not all police officers dealing with such cases will have had appropriate training in sexual offence investigating techniques.

Owing to shortages of trained medical staff, complainants often have to wait many hours before forensic examinations can be carried out. Their distress is worsened by advice not to wash, so as to preserve evidence. The procedure often

\section{Correspondence to: Dr Martin Wiese}

${ }^{1}$ University Hospital Lewisham, Lewisham High Street, London SE13 6LH; ${ }^{2}$ Archway Sexual Health Clinic, Whittington Hospital, London N19 5NF;

${ }^{3}$ The Haven Camberwell, Sexual Assault Referral Centre, Department of Sexual Health, King's College Hospital, London SE5 9RS, UK

E-mail: wiese@doctors.org.uk takes place in a 'victim examination suite' within a police station rather than a health service facility. Infrequent use of the rooms and high staff turnover mean that such facilities are difficult to keep adequately clean and stocked. The forensic medical examiner is often male and may not have specialist training in sexual offence examinations.

Finally, although psychosocial support is offered by many voluntary organizations, local access to such agencies is variable. ${ }^{4}$ It is therefore easy to see why many complainants of sexual assault do not have all their needs met and why the handling of forensic evidence is frequently suboptimal.

\section{ADVANCES}

The need for specialist services, termed sexual assault referral centres, has long been recognized. ${ }^{5}$ In the USA and Australia, such units have existed for over a decade and are often led by specially trained sexual assault nurse examiners. ${ }^{6,7}$ The first centre in the UK was instituted at St Mary's Hospital in Manchester in $1986 .{ }^{8}$

'The Haven Camberwell', the first such service in London, opened in May 2000 as part of the Department of Sexual Health at King's College Hospital. Jointly funded by the National Health Service and the Metropolitan Police, it works closely with the latter's initiative on sexual violence, Project Sapphire. ${ }^{9}$ The aim of this innovative partnership, which has undergone detailed evaluation, ${ }^{10}$ is to combine optimal initial case management by police officers trained in sexual offences investigative techniques with the best available medical care. The centre conducts over 850 examinations each year, thus dealing with about $8 \%$ of the rapes reported in England and Wales. ${ }^{11}$ Since opening, it has cared for more than 3000 individuals, including at least 100 children aged under 12 . One-fifth of its clients - the preferred term at the centre-are referred by other agencies or refer themselves directly, without initial police involvement.

With the launch of two similar centres - 'The Haven Paddington' at St Mary's Hospital and 'The Haven Whitechapel' at the Royal London Hospital_on 15 July 2004 , the service is now available to all Londoners ${ }^{12}$ and the Home Office is supporting the development of further services in areas of the country that do not yet have access to a sexual assault referral centre. A full list of all sexual assault referral centres currently in operation can be found 


\section{Box 1 Choices for clients at 'The Haven'}

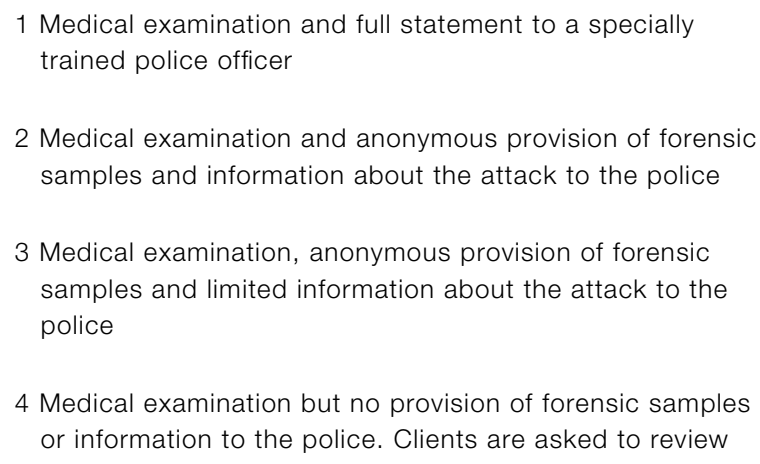

2 Medical examination and anonymous provision of forensic samples and information about the attack to the police

3 Medical examination, anonymous provision of forensic samples and limited information about the attack to the police

4 Medical examination but no provision of forensic samples or information to the police. Clients are asked to review their decision after two months

5 No medical examination but completion of a form providing details about the attack to the police

6 Medical and/or psychological support services only

7 Meeting with the police at 'The Haven' to discuss the details of the assault, without making it an official allegation

In options 2-7, clients can choose to remain anonymous or provide some details about themselves to the police. For example, they may not want the police to know their name and/or address but would be prepared to give their age, gender and ethnic background. They can also decide whether or not they want staff from 'The Haven' or the police to discuss the outcomes of the investigations into the attack with them. Clients may change all these decisions at any time.

at the Project Sapphire website [www.met.police.uk/ sapphire/].

\section{WHAT 'THE HAVEN CAMBERWELL’ OFFERS}

The centre serves women, men and children seeking help after acute sexual assault; children subjected to ongoing sexual abuse are referred to local community paediatric services. 'The Haven Camberwell' accepts referrals from the police and around 40 NHS organizations in South London, and is also open to clients who wish to refer themselves directly. It operates 24 hours a day, 7 days a week, by appointment arranged by telephone. Clients can usually be seen within one hour, although they may have to wait a little longer if another examination is in progress. Specially trained female doctors known as sexual offence examiners conduct forensic examinations; children under 13 years of age are examined jointly with a community paediatrician. Psychosocial crisis support is immediately available. The need for post-coital contraception as well as post-exposure prophylaxis against blood-borne viruses such as HIV and sexually transmitted infections is assessed. After the examination a shower is provided together with new clothing to replace any items retained for evidence. All clients are offered follow-up.

Forensic examination at 'The Haven' is offered without mandatory police involvement. Clients may choose from a range of options by which they can control the extent of their disclosure, and are welcome even if they seek only medical or psychosocial support (see Box 1). Forensic samples can be stored indefinitely and so are available if a client decides to disclose more information later. The flexibility of this innovative approach is valued not only by clients but also by the police, since the additional intelligence as well as DNA evidence gained has already led to identification of several assailants, including serial rapists.

\section{IMPROVING EMERGENCY MEDICAL CARE}

One in eleven complainants of sexual assault initially seeks help in a hospital emergency department ("The Haven Camberwell', unpublished). Most emergency physicians, however, have little personal experience in caring for such patients and the British Association for Emergency Medicine's current guidelines for the management of assault victims do not contain specific advice about sexual assault. ${ }^{13}$

Cooperation with a specialist centre such as 'The Haven' helps not only to optimize care for complainants of sexual assault but also simplifies their management in the emergency department. At King's College Hospital, an interdepartmental working party of consultants, trainees and nurse specialists has developed a local model of such cooperation. It allows emergency department personnel to concentrate on acute medical care, which should always take priority over forensic considerations, and on the collection of 'early evidence' (see below).

Figure 1 shows the flowchart guiding staff through the essential management steps that need to be considered. The protocol is being adopted by an increasing number of hospitals across South London served by 'The Haven'. Participating emergency departments have all appointed a named sexual assault link nurse to ensure that staff awareness and training is maintained.

\section{COLLECTING EVIDENCE IN THE EMERGENCY DEPARTMENT}

Although systematic gathering of forensic medical evidence is the responsibility of the sexual assault referral centre or, where such a service is not yet available, a forensic medical examiner, certain samples should be routinely collected in the emergency department. These include a mouth swab to help detect DNA evidence of oral penetration, which few clients will disclose initially, and a urine specimen to assist 


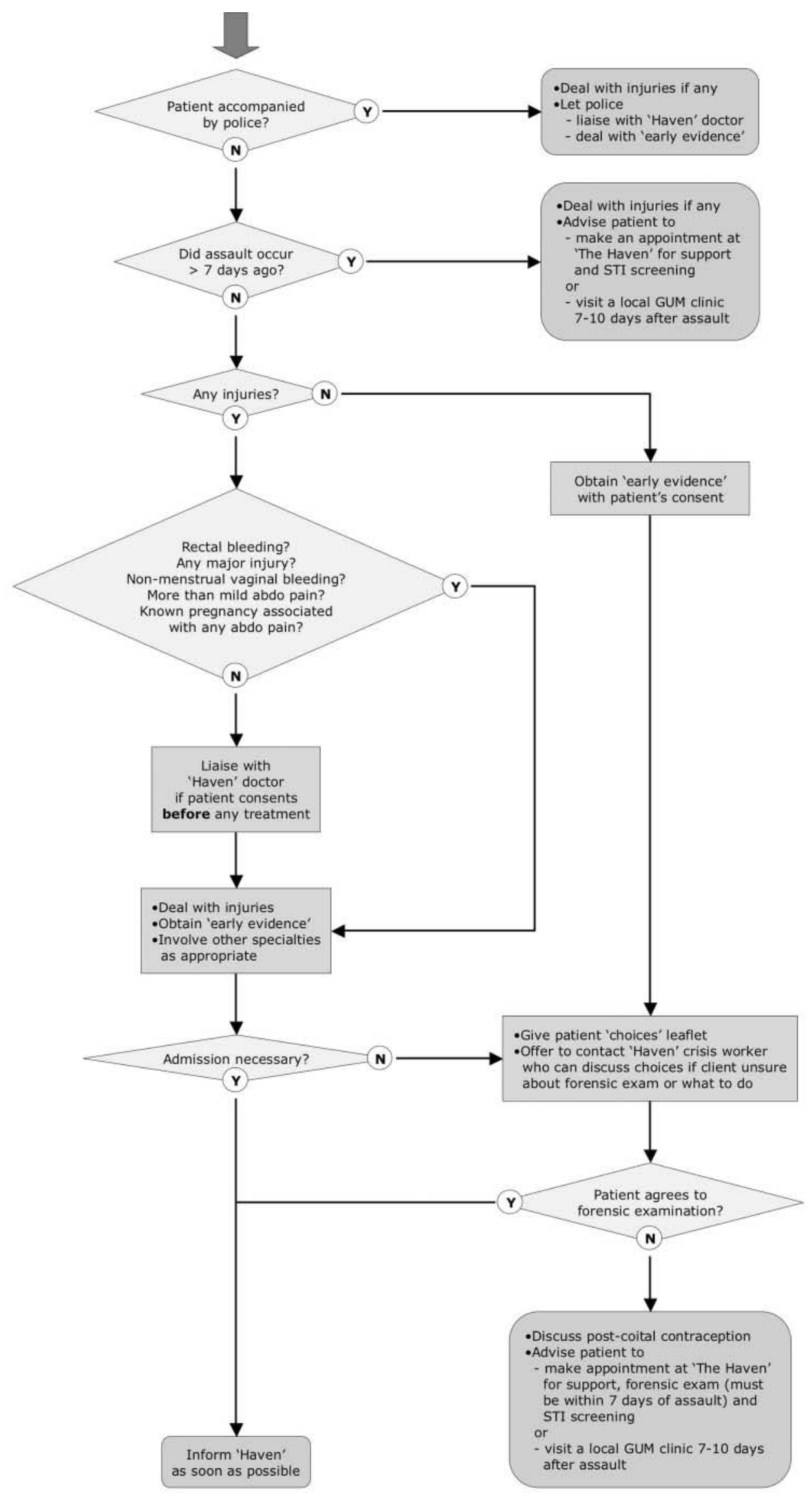


Box 2 Forensic medical evidence and consent

- Forensic medical examination and gathering of samples both require informed written consent. If patients are intoxicated or clinically unstable early evidence may be collected and stored for later consent, but any forensic medical examination must be delayed until the patient has regained capacity.

- The competence of patients under 16 years of age to provide informed consent requires assessment along Fraser guidelines (formerly known as Gillick competency) [Ref. 14] and these patients should be given an opportunity for discussion with an appropriate adult, ideally a family member aged over 18 years. A social worker may have to be involved if an appropriate adult is not available. Similar principles apply to individuals with learning difficulties.

- Patients who are not able to understand the relevant information in English must be given access to a translator to conduct the discussion before consent can be obtained. It is not considered appropriate to use a friend or family member of the client for this purpose, since a translator who is not impartial may influence the patient's choices. The police are responsible for providing a translator to any client they refer to 'The Haven Camberwell'.

establishment of evidence of drug or alcohol facilitated sexual assault.

The samples (together with written consent, see Box 2) should be requested as soon as feasible, as patients should ideally not pass urine and neither smoke nor drink before they are obtained. The 'Early Evidence Kit', a small pack containing the necessary containers, instructions and consent form has been developed for this purpose (see Figure 2) and is available from the Forensic Science Service

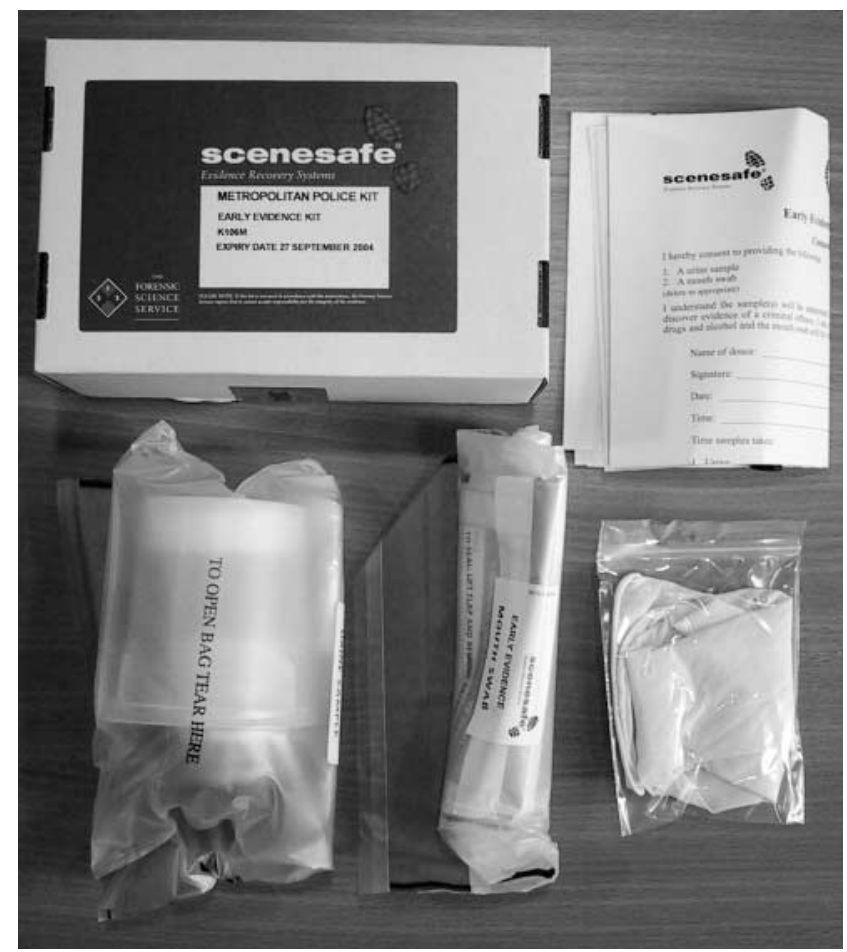

Figure 2 Contents of the 'Early Evidence Kit-K106'. [Reproduced by permission of the Forensic Science Service] for use both by healthcare professionals and by police officers. ${ }^{15}$

Other items that should be collected for later forensic examination include any removed clothes, swabs used for wound cleaning or bladder catheterization as well as tampons and sanitary towels. Paper sacks for clothing and plastic evidence bags for other items are available for this purpose from the police. Errors in the handling of evidence can be counterproductive, since the defence team may use them against the case. Local sexual offence investigating officers should therefore be invited regularly to provide brief training on how to collect and package all such items and how to maintain the 'chain of evidence'.

'The Haven' is currently developing an educational package intended to provide guidance and training for all of those involved in the emergency care for people who have been sexually assaulted. The project is funded by the Home Office and will be made available both as a DVD and on the Internet.

It should be noted that the detection of the alleged assailant's DNA on forensic specimens collected from the complainant merely suggests that a sexual act has taken place. Its presence alone does not prove that the act was non-consensual, but in the updated Sexual Offences Act which came into force in May 2004 the onus is on the defendant to prove that reasonable measures were taken to gain consent for sexual intercourse. Previously, the burden of proof lay with the complainant. ${ }^{16}$

\section{CONCLUSIONS}

Conventional services can leave complainants of sexual assault with unmet needs. Fundamental system changes will be necessary if better care for this vulnerable group of people is to be achieved, along with higher conviction rates. The establishment of specialist sexual assault referral centres offering better access to forensic services and psychosocial crisis support is an important part of that process and deserves to be driven forward at both central and local levels.

Close cooperation between existing services and the new specialist units is crucial and requires clear guidance for emergency department staff. The model described in this paper is currently being adopted across London and could be used wherever efforts are being made to improve services for those patients.

Acknowledgments We thank Saffron Schofield, emergency nurse practitioner, and Dr Edward Glucksman, Clinical Director, Kings' College Hospital Emergency Department, for their contributions to the working party. 


\section{REFERENCES}

1 Myhill A, Allen J. Rape and Sexual Assault of Women: the Extent and Nature of the Problem. British Crime Survey. London: Home Office, 2002

2 Painter K. Wife Rape, Marriage and The Law. Manchester: Manchester University Press, 1991

3 Kelly L, Regan L. Rape: Still a Forgotten Issue. Briefing document for strengthening the linkages - consolidating the European Network Project. London: Child of Woman Abuse Studies Unit, London Metropolitan University, 2003

4 Rape Crisis Centre [www.rapecrisis.co.uk] accessed 27 November 2004

5 Duddle M. The need for sexual assault centres in the United Kingdom. BMJ 1985;290:771-3

6 Selig C. Sexual assault nurse examiner and sexual assault response team (SANE/SART) program. Nurs Clin North Am 2000;35:311-19

7 Derhammer F, Lucente V, Reed JF, et al. Using a SANE interdisciplinary approach to care of sexual assault victims. Jt Comm J Qual Improv 2000;26:488-96

8 Lacey HB. Sexually transmitted diseases and rape: the experience of a sexual assault centre. Int J STD AIDS 1990;1:405-9
9 Project Sapphire [www.met.police.uk/sapphire/index.htm] accessed 27 November 2004

10 HM Crown Prosecution Service Inspectorate and HM Inspectorate of Constabulary. A Report on the Joint Inspection and Prosecution of Cases Involving Allegations of Rape. London: Home Office, 2002

11 Kerr E, Cottee C, Chowdhury R, et al. The Haven: a pilot referral centre in London for cases of serious sexual assault. Br J Obstet Gynaecol 2003; 110:1-5

12 The Haven Paddington and The Haven Whitechapel [www. thehavens.org.uk/articles/story_6.htm] accessed 27 November 2004

13 British Association of Emergency Medicine, Association of Police Surgeons of Great Britain and Royal College of Nursing Accident \& Emergency Association. Guidelines for the Management of Assault Victims. London: BAEM/APSGB/RCN, 1987

14 Forensic Science Service [www.forensic.gov.uk/forensic_t/inside/ news/list_press_release. php?case $=12 \& \mathrm{y}=2002]$ accessed 27 November 2004

15 Gillick v. West Norfolk and Wisbech Area Health Authority [1986] AC 112

16 Sexual Offences Act 2003 [www.legislation.hmso.gov.uk/acts/ acts2003/20030042.htm] accessed 27 November 2004 